\title{
The effect of Acacia senegal as potential prebiotic on obese gut microbiota
}

\author{
${ }^{1,4}$ Ahallil, H., ${ }^{1, *}$ Maskat, M.Y., ${ }^{3}$ Abdullah, A. and ${ }^{2}$ Sarbini, S.R. \\ ${ }^{1}$ Department of Food Science, Faculty of Science and Technology, Universiti Kebangsaan \\ Malaysia, 43600 Bangi, Selangor, Malaysia \\ ${ }^{2}$ Department of Crop Science, Faculty of Agricultural and Food Sciences, Universiti Putra \\ Malaysia Bintulu Campus, Jalan Nyabau, 97008 Bintulu, Sarawak, Malaysia \\ ${ }^{3}$ Malaysian Islamic University, Block 1, MkN embassy Techzone, 63000 Cyberjaya, Selangor, Malaysia \\ ${ }^{4}$ Department of Plant Production, Faculty of Agriculture, University Benghazi, Al Kufra, Libya
}

\begin{abstract}
Article history:
Received: 21 October 2019

Received in revised form: 24

November 2019

Accepted: 30 December 2019

Available Online: 27 January 2020
\end{abstract}

\section{Keywords:}

Acacia senegal,

Prebiotic,

Obesity,

Colonic fermentation

DOI:

https://doi.org/10.26656/fr.2017.4(3).350

\begin{abstract}
Gut microbiota is able to affect body weight by fermenting dried fibers and generating short chain fatty acids (SCFA). Acacia senegal is an edible dried which might have potential prebiotic activity. The aim of this study was to investigate the effect of Acacia senegal as potential prebiotic on the composition and activity of human colonic microbiota of obese healthy subjects. In order to identify a potential prebiotic effect of Acacia senegal on obese individuals, anaerobic, $\mathrm{pH}$-controlled batch cultures system was applied. The growth of different microbes and the concentration of lactic acid and short chain fatty acids were studied at $0,6,12,24$ and $36 \mathrm{hrs}$ using fluorescent in situ hybridization (FISH) and HPLC respectively. The results showed that Acacia senegal was able to simulate the microbiota population since it significantly increased $(\mathrm{P}>0.05)$ the population of Bifidobacterium and decreased the population of Clostridium. Moreover, the supplement of Acacia senegal to the models significantly modulate short-chain fatty acid concentration. These findings clearly identified Acacia senegal as an additional contributing factor to the gut microbiota of obese subject and suggest that Acacia senegal could be an interesting supplement for obese human which might help to control obesity.
\end{abstract}

\section{Introduction}

The prevalence of obesity is escalating in communities worldwide (Nguyen and El-Serag, 2010). It has been proposed that the current obesity epidemic may have been caused by a discrepancy between the physiological mechanisms for maintaining energy balance, and the composition of the current diet (Eaton and Konner 1985). During the last decade, however, diet has altered significantly to food with high energy density that has low dietary fiber, which led to low production of satisfaction and satiety signals (Prentice and Jebb 2003; Popkin et al., 2012).

Bodyweight may possibly be stimulated and managed by increasing the consumption of dietary fiber using a specific type of fiber. Several researchers claimed that large consumption of dietary fiber, such as gum arabic (GA) is linked with considerable and favorable impact on metabolism of fat (Ali et al., 2009; Slavin, 2003). GA, an edible dried sticky exudate from two types of Acacia (Acacia seyal and Acacia senegal) is rich in non-viscous soluble fiber (Slavin, 2013). In the area of food industry and pharmaceutical, GA has been widely used as an emulsifier and preservative (Ali et al., 2009). GA was used in both North Africa and Middle East as oral hygiene material (Tyler et al., 1977). Successfully, dietary fiber showed a great ability to manage weight by promoting satiation and satiety (Chandalia et al., 2000). However, prebiotic has the greatest health benefits on human gut where it can modulate the population of salutary bacteria. In general, microbiota plays the main role in gut function (Van Nuenen et al., 2004). Generally, Bifidobacteria and Lactobacilli had significant path in preserving intestinal well-being attributable to their impact on the stability of the immune system (Peran et al., 2007; Sartor, 2008; Zeuthen et al., 2010) and their inhibiting efficacy on pathogens (Collado et al., 2007; Fukuda et al., 2011). Furthermore, for the desired health effect, the ingestion of sufficient and effective prebiotic is required (European Food Safety Authority, 2010). Postbiotics are the principle product of the probiotic metabolism of 
nondigestible carbohydrates in the gut and one of these major postbiotics is short chain fatty acids (SCFAs) (Wong et al., 2006; Lunn and Buttriss, 2007). The process of bacterial fermentation is an energy harvest system for undigested material, delivering energy that is impassable to be absorbed in the small bowel and is utilized as the main energy source for some species (McNeil, 1984; Popovich et al., 2005). Three acids namely (acetate, propionate and butyrate) are the major acids generated by the fermentation of bacteria (Cummings et al., 1987). The different percentage and rate of SCFAs production during fermentation are dependent on the kind of prebiotic and the microbiotas (Brinkworth et al., 2009; Murphy et al., 2010). Furthermore, Reimer (2012) revealed that adult rat that devoured a weaning regimen supplied with prebiotic was preserved from obesity when compared with a westernstyle diet high in fat.

Proposed mechanism by which fiber may protect us against obesity is based on the beneficial impact that such kind of metabolites have on host energy balance, e.g. by mediating the secretion of gut hormones involved in the regulation of energy metabolism and food intake (including leptin, peptide YY and glucagon-like peptide1) (Freeland and Wolever, 2010; Tarini and Wolever, 2010). Thus, high consumption of prebiotic would be a significant way to decrease the hazard of gaining weight (Liu et al., 2003; Anderson et al., 2009).

After all, SCFAs could only produce 5 to $10 \%$ of total dietary energy (Royall et al., 1990). Nevertheless, neoteric study dug in such risk-reduction role. A growing body of evidence illustrated that the concentration of SCFAs varies among the source of microbiota, either from lean or obese individuals. Although it is well known that prebiotic affect obesity and performed in a broad domain of health benefits, further research is needed to fully elucidate the growth of gut microbiota and the production of SCFAs which led to different and numerical effects. However, published research often focuses on positive physiological impacts associated with diet supplementation. Nowadays, there is a number of in vitro studies mimicking colon fermentation from various sources of microbiota (lean, obese). Given this background, the present work aimed studying the effect of Acacia senegal as potential prebiotic on obesity by using colon model applied with faecal microbiota from obese individuals.

\section{Material and methods}

\subsection{Samples}

In this research, the gum arabic samples (Acacia senegal) was collected from a Sudanese market at North
Kordofan. The positive control (Inulin) was from chicory root (Warcoing, Belgium).

\subsection{Faecal inoculation}

Four healthy male adult donors between the age of 20 to 30 years old and with BMI $30-35 \mathrm{~kg} / \mathrm{m}$ was carefully selected. Before the beginning of the study, the donors have been checked for their health status. The donors did not take any antibiotic treatment and did not use any pre or probiotic diet since the last six months before the donation. Fresh faecal sample was assembled in $50 \mathrm{~mL}$ plastic sterile at University Putra Malaysia, Bintulu campus on the same day of the fermentation. Faecal inoculums were prepared by diluting the faecal with sterile phosphate buffered saline (PBS) $(1: 10 \mathrm{w} / \mathrm{w})$ (0.1 M, pH 7.4) and then put in a stomacher at normal speed for $2 \mathrm{~min}$ (Stomacher 400, Seward, West Sussex, UK) for homogenization (Ahallil et al., 2018).

\subsection{In vitro fermentation}

The impact of Acacia senegal on the growth of microbiota from the gut and postbiotic production was carried out in customised glass vessels of anaerobic $\mathrm{pH}$ controlled batch culture fermentation system. Aseptically $45 \mathrm{~mL}$ of pre-sterilized basal nutrient medium was filled in $100 \mathrm{~mL}$ fermenter vessels (Sarbini and Rastall, 2011). The basal medium was prepared according to Sarbini and Rastall (2011). A day before the fermentation, the basal medium was persistently supplied with oxygen $(15 \mathrm{~mL} /$ min) and stirred overnight. The Acacia senegal and inulin were added with the concentration of $1 \% \mathrm{w} / \mathrm{w}$ $(0.5 \mathrm{~g}$ in $50 \mathrm{~mL})$. Before the addition of the substrates, $10 \%$ of fresh inoculums (fecal slurry) were added. The circulating water bath was set at $37^{\circ} \mathrm{C}$ for all batch vessels. The $\mathrm{pH}$ was controlled at 6.8 using $\mathrm{pH}$ controller. The experiments were carried out for $36 \mathrm{hrs}$ and the sampling for FISH and SCFA analysis was at 0, 6, 12, 24 and $36 \mathrm{hrs}$. Four replicates from four different fecal donors were used to performer this study.

\subsection{Bacterial enumeration by fluorescence in situ hybridization (FISH)}

Fluorescence in situ hybridization was used to enumerate the gut microbiota. Specific types of the $16 \mathrm{~S}$ ribosomal ribonucleic acid molecule bonded with synthetic oligonucleotide probes and labelled with the fluorescent dye $\mathrm{Cy} 3$ were used to count the different bacterial groups (Table 1). All samples were treated with filtered paraformaldehyde $(\mathrm{pH} 7.2)$ in a ratio of $1: 3(\mathrm{v} / \mathrm{v})$ for $4 \mathrm{hrs}$ in $4^{\circ} \mathrm{C}$. Phosphate buffered saline with $0.1 \mathrm{~m}$ and $\mathrm{pH} 7.0$ was used to wish the sample twice and then centrifuged at $13000 \times g$ for 5 mins. The cells were resuspended in phosphate buffered saline/ ethanol $(99 \%)$ 
Table 1. 16S rRNA oligonucleotide probes used in FISH analysis of bacterial populations.

\begin{tabular}{|c|c|c|c|}
\hline Probe Code & Target group & Sequence $\left(5^{\prime}-3^{\prime}\right)$ & Reference \\
\hline Chis150 & $\begin{array}{l}\text { Most of the Clostridium histolyticum } \\
\text { group (Clostridium clusters I and II) }\end{array}$ & TTATGCGGTATTAATCTYCCTTT & Franks et al. (1998) \\
\hline Lab158 & Lactobacillus-Enterococcus & GGTATTAGCAYCTGTTTCCA & Harmsen et al. (1999) \\
\hline Bac303 & $\begin{array}{l}\text { Most Bacteroidaceae and Prevotellaceae, } \\
\text { some Porphyromonadaceae }\end{array}$ & CCAATGTGGGGGACCTT & Manz et al. (1996) \\
\hline Bif164 & Bifidobacterium spp. & CATCCGGCATTACCACCC & Langendijk et al. (1995) \\
\hline
\end{tabular}

at $1: 1(\mathrm{v} / \mathrm{v})$ after which the pellets were stored at $-20^{\circ} \mathrm{C}$. In order to gain a computable number of bacteria in every slide, dilution of the cells was applied by using PBS. For the enumeration, $20 \mu \mathrm{L}$ of each diluted sample was added to each well of six-well polytetrafluoroethylene/ poly-L-lysine-coated slide. Drying step with $46^{\circ} \mathrm{C}$ for 15 mins was applied to all slides. Dehydration with various concentration of ethanol (50, 80 and 96\%) was also applied to all slide for 3 mins. The ethanol was then evaporated in oven dryer for 2 mins.

Hybridisations were carried out by adding $50 \mu \mathrm{L}$ hybridisation mixture (which consisting of $45 \mu \mathrm{L}$ hybridisation buffer) and $5 \mu \mathrm{L}$ different probe (Chis150, Lab158, Bac303 and Bif164) to each single well and kept to hybridise for $4 \mathrm{hrs}$ in a microarray hybridisation incubator. Next, hybridized slides were washed in washing buffer for 15 mins then followed with dipping in cool water for a few seconds and dried using compressed air. Before covering the slide with coverslip, $5 \mu \mathrm{L}$ of polyvinyl alcohol was added for each and every well on the slide. The enumeration of each bacteria group was done by taking the average of 15 reading times from 15 different areas using epifluorescence microscope with reflected fluorescence attachment. (Sarbini and Rastall, 2011).

\subsection{Analysis of lactic acid and short chain fatty acids}

Ion-exclusion HPLC system (SHIMADZU SPD20A) connected with UV-VIS detector was used to detect the short chain fatty acids namely (acetate, propionate and butyrate) and lactic acid. The column applied in this research was Ionexclusion Rezex ROAOrganic Acid $\mathrm{H}^{+}(8 \%)$ column. The eluent utilized in this study was $0.0025 \mathrm{mmol} / \mathrm{L}$ of sulphuric acid. The samples were prepared by centrifuging all samples from batch culture vessels for $10 \mathrm{mins}$ at $13000 \times \mathrm{x}$ then the supernatant filtered with $0.2 \mathrm{~mm}$ polycarbonate filters. A total of $15 \mu \mathrm{L}$ of the filtered supernatants was immediately injected into an HPLC-UV system. For HPLC, the column was heated to $40^{\circ} \mathrm{C}$ and the flow rate at $0.5 \mathrm{~mL} / \mathrm{min}$. The calculation of the SCFAs concentration was done using calibration curves generated using external standards namely lactate, acetate, propionate, and butyrate.

\subsection{Statistical analysis}

The data were statistically analyzed using SPSS 23 software with two-way ANOVA and one-way ANOVA. Duncan test was applied to study the significant differences $(p<0.05)$ between.

\section{Results and discussion}

FISH analyses were performed to enumerate different bacterial species in fermented substrates collected from the study group. Statically, there was a significant difference between the samples types and also the fermentation time (Table 2).

Table 2. Mean value of Bifidobacterium (Bif) population ( $\log _{10}$ cells $/ \mathrm{mL}$ batch culture fluid) in the colon model at 0,6 , 12, 24 and 36 hrs inoculated with feces microbiota from obese

\begin{tabular}{cccc}
\hline Bif & Senegal & Inulin & Control \\
\hline $0 \mathrm{hr}$ & $7.83 \pm 0.21^{\text {ef }}$ & $7.83 \pm 0.21^{\text {ef }}$ & $7.83 \pm 0.21^{\text {ef }}$ \\
$6 \mathrm{hrs}$ & $8.18 \pm 0.13^{\text {de }}$ & $8.45 \pm 0.49^{\text {bcd }}$ & $8.07 \pm 0.19^{\text {de }}$ \\
$12 \mathrm{hrs}$ & $8.29 \pm 0.15^{\text {cd }}$ & $8.9 \pm 0.3^{\mathrm{a}}$ & $8.06 \pm 0.18^{\mathrm{de}}$ \\
$24 \mathrm{hrs}$ & $8.61 \pm 0.13^{\mathrm{abc}}$ & $9.02 \pm 0.28^{\mathrm{a}}$ & $7.85 \pm 0.23^{\text {ef }}$ \\
$36 \mathrm{hrs}$ & $8.82 \pm 0.3^{\mathrm{ab}}$ & $8.76 \pm 0.15^{\mathrm{ab}}$ & $7.59 \pm 0.46^{\mathrm{f}}$ \\
\hline
\end{tabular}

Values are expressed as mean \pm SD $(n=4)$. Different superscript letters are significantly different $(\mathrm{P}<0.05)$.

The growth of Bifidobacterium was not significant at the first $6 \mathrm{hrs}$ of fermentation $\left(8.18 \log _{10}\right)$, but after 12 , 24 and up to $36 \mathrm{hrs}$ of Acacia senegal fermentation, the growth was significant at $8.29 \log _{10}, 8.61 \log _{10}$ and 8.82 $\log _{10}$ respectively (Table 2). Inulin showed different contribution by the obese microbiota, a significant increase of Bifidobacterium was observed from the first $6 \mathrm{hrs}\left(8.45 \log _{10}\right)$ of incubation up to 12 , furthermore, 36 hrs of fermentation did not produce any significant change. Comparing between samples, after $6 \mathrm{hrs}$ of fermentation no significant difference was observed. At $12 \mathrm{hrs}$, inulin showed a higher $(\mathrm{p}<0.05)$ growth compared to Acacia senegal and control. Furthermore, up to $36 \mathrm{hrs}$ showed sample produced growth not different from inulin. This shows Acacia senegal has the potential to match inulin as prebiotic. In general, the findings of this study were in line with Kalliomaki et al. (2008) who stated that; a minimum population of Bifidobacteria at childbirth has been linked with gaining weight later in childhood. Furthermore, Collado et al. 
(2010) claimed that overweight motives procreate neonates that have a lessened population of Bifidobacteria, which refer to that obesogenic microbiota is an 'inheritable' trait.

Selectively, the growth of Bifidobacteria was spotted to significantly expand in obese individuals after the fermentation of Acacia senegal and inulin. As obtained by Korpela et al. (2014), at the beginning of an intrusion there was little the abundance of Bifidobacterium spp. the high growth was optioned after the administration of prebiotic. Additionally, Rycroft et al. (2001) and Roberfroid et al. (1998) early noted such inverse relationship for different periodic such as FOS. Inulin also showed a great increase in Bifidobacteria (Ahallil et al., 2018). Phenomenal growth of Bifidobacterium spp has been spotted in obese mice fed with specific diet enhanced with inulin (Cani et al., 2009). FISH analyses of the microbiota proved the ability of Acacia senegal to modulate the colon.

Bacteroide showed the difference in growth between samples and fermentation (Table 3). There was no significant growth of Bacteroidaceae from $0 \mathrm{hr}$ up to 12 hrs of Acacia senegal fermentation. The significant growth of Bacteroidaceae only observed after $24 \mathrm{hrs}$ of Acacia senegal fermentation. Simultaneous, the fermentation of inulin illustrated that Bacteroidaceae significantly increase $(\mathrm{P}<0.005)$ from the first $12 \mathrm{hrs}$ compared to $0 \mathrm{hr}$ (Table 3). However, comparing between samples, there was no significant growth of of Bacteroidaceae at $6 \mathrm{hrs}$ of inoculation. But at $12 \mathrm{hrs}$, inulin showed a higher $(\mathrm{p}<0.05)$ growth of Bacteroidaceae compared to Acacia senegal and control. However, there was no significant difference in the growth of Bacteroidaceae between Acacia senegal and inulin at 24 hrs and 36 hrs. Bacteroidetes showed significant growth in distal colon system when treated with Acacia senegal, these finding in agreement with Terpend et al. (2013) who illustrated high growth of Bacteroidetes in mice when the fed with $10 \mathrm{~g}$ of gum arabic per day for 4 weeks. From the result, it can be noted that fermentation of inulin was higher and faster than Acacia senegal on promoting the growth of Bifidobacterium and

Table 4. Mean value of lactobacilli (Lab) population $\left(\log _{10}\right.$ cells/mL batch culture fluid) in the colon model at $0,6,12,24$ and $36 \mathrm{hrs}$ inoculated with feces microbiota from obese.

\begin{tabular}{cccc}
\hline Lab & Senegal & Inulin & Control \\
\hline $0 \mathrm{hr}$ & $7.95 \pm 0.3^{\mathrm{cd}}$ & $7.95 \pm 0.3^{\mathrm{cd}}$ & $7.95 \pm 0.3^{\mathrm{cd}}$ \\
$6 \mathrm{hrs}$ & $8.02 \pm 0.27^{\mathrm{bcd}}$ & $8.26 \pm 0.36^{\mathrm{abc}}$ & $8.11 \pm 031^{\mathrm{abcd}}$ \\
$12 \mathrm{hrs}$ & $8.24 \pm 0.22^{\mathrm{abc}}$ & $8.45 \pm 0.27^{\mathrm{ab}}$ & $8.09 \pm 0.24^{\mathrm{bcd}}$ \\
$24 \mathrm{hrs}$ & $8.32 \pm 0.16^{\mathrm{abc}}$ & $8.57 \pm 0.35^{\mathrm{a}}$ & $7.93 \pm 0.28^{\mathrm{cd}}$ \\
$36 \mathrm{hrs}$ & $8.36 \pm 0.19^{\mathrm{abc}}$ & $8.36 \pm 0.29^{\mathrm{abc}}$ & $7.74 \pm 0.28^{\mathrm{d}}$ \\
\hline
\end{tabular}

Values are expressed as mean $\pm \mathrm{SD}(\mathrm{n}=4)$. Different superscript letters are significantly different $(\mathrm{P}<0.05)$.
Bacteroidetes. The fermentation rate of GA was slow as compared with inulin that is because of the molecular weight of the substrates.

Table 3. Mean value of Bacteroidaceae (Bac) population ( $\log _{10}$ cells $/ \mathrm{mL}$ batch culture fluid) in the colon model at 0,6 , 12, 24 and $36 \mathrm{hrs}$ inoculated with feces microbiota from obese.

\begin{tabular}{cccc}
\hline Bac & Senegal & Inulin & Control \\
\hline $0 \mathrm{hr}$ & $8.28 \pm 0.18^{\text {ef }}$ & $8.28 \pm 0.18^{\text {ef }}$ & $8.28 \pm 0.18^{\text {ef }}$ \\
$6 \mathrm{hrs}$ & $8.38 \pm 0.19^{\text {def }}$ & $8.57 \pm 0.14^{\text {bcde }}$ & $8.42 \pm 0.16^{\text {cdef }}$ \\
$12 \mathrm{hrs}$ & $8.46 \pm 0.15^{\text {cdef }}$ & $8.87 \pm 0.11^{\mathrm{ab}}$ & $8.36 \pm 0.15^{\text {def }}$ \\
$24 \mathrm{hrs}$ & $8.65 \pm 0.23^{\text {abcd }}$ & $8.91 \pm 0.3^{\mathrm{a}}$ & $8.17 \pm 0.12^{\mathrm{fg}}$ \\
$36 \mathrm{hrs}$ & $8.72 \pm 0.28^{\mathrm{abc}}$ & $8.86 \pm 0.3^{\mathrm{ab}}$ & $7.95 \pm 0.2^{\mathrm{g}}$ \\
\hline
\end{tabular}

Values are expressed as mean \pm SD $(n=4)$. Different superscript letters are significantly different $(\mathrm{P}<0.05)$.

The growth of lactobacilli during the fermentation of Acacia senegal and inulin showed in Table 4. Comparing to $0 \mathrm{hr}$, lactobacilli did not grow with Acacia senegal. However, comparing between samples, the growth of lactobacilli was not significantly different at $6 \mathrm{hrs}, 12 \mathrm{hrs}$ and $24 \mathrm{hrs}$. But at $36 \mathrm{hrs}$, it was significantly high in growth with Acacia senegal and inulin. There was significantly low growth of lactobacilli which only noted $36 \mathrm{hrs}$ of fermentation. As observed by Sarbini et al. (2014), oligosaccharides with lower molecular-weight might be quickly metabolized than the oligosaccharides with high molecular-weight. This may be due to nonreducing ends of the carbohydrate which preferred by lactobacilli (Gibson et al., 2004; Sarbini and Rastall, 2011).

There was a slight increase in Clostridium growth at first $6 \mathrm{hrs}$ of Acacia senegal fermentation compared to 0 $\mathrm{hr}$, and after $12 \mathrm{hrs}$ of fermentation the growth dramatically decreased and showed no significant different with $0 \mathrm{hr}$ (Table 5). Moreover, the growth of Clostridium during the fermentation of inulin was significant at $12 \mathrm{hrs}$ and $24 \mathrm{hrs}$ compared to $0 \mathrm{hr}$, but at $36 \mathrm{hrs}$ showed no significant difference compared to 0 hr. However comparing between samples, there was no significant difference during all fermentation times. These findings are also in line with the results from previous in vivo studies (Wyatt et al., 1986; Cherbut et

Table 5. Mean value of Clostridium (Chis) population $\left(\log _{10}\right.$ cells/mL batch culture fluid) in the colon model at $0,6,12,24$ and $36 \mathrm{hrs}$ inoculated with feces microbiota from obese.

\begin{tabular}{cccc}
\hline Chis & Senegal & Inulin & Control \\
\hline $0 \mathrm{hr}$ & $7.33 \pm 0.12^{\text {de }}$ & $7.33 \pm 0.12^{\mathrm{de}}$ & $7.33 \pm 0.12^{\mathrm{de}}$ \\
$6 \mathrm{hrs}$ & $7.76 \pm 0.13^{\mathrm{a}}$ & $7.58 \pm 0.12^{\mathrm{abcd}}$ & $7.5 \pm 0.2^{\mathrm{abcd}}$ \\
$12 \mathrm{hrs}$ & $7.59 \pm 0.14^{\mathrm{abcd}}$ & $7.73 \pm 0.29^{\mathrm{ab}}$ & $7.52 \pm 0.03^{\mathrm{abcd}}$ \\
$24 \mathrm{hrs}$ & $7.48 \pm 0.18^{\mathrm{bcde}}$ & $7.68 \pm 0.2^{\mathrm{abc}}$ & $7.41 \pm 0.03^{\mathrm{de}}$ \\
$36 \mathrm{hrs}$ & $7.42 \pm 0.22^{\text {cde }}$ & $7.59 \pm 0.17^{\mathrm{abcd}}$ & $7.22 \pm 0.05^{\mathrm{e}}$ \\
\hline
\end{tabular}

Values are expressed as mean \pm SD $(n=4)$. Different superscript letters are significantly different $(\mathrm{P}<0.05)$. 
Table 6. Mean value of lactate concentration $(\mathrm{mM})$ in the colon model at $0,6,12,24$ and $36 \mathrm{hrs}$ inoculated with feces microbiota from obese individuals.

\begin{tabular}{cccc}
\hline Lactate & Senegal & Inulin & Control \\
\hline $0 \mathrm{hr}$ & $76.3 \pm 6.7^{\mathrm{a}}$ & $76.3 \pm 6.7^{\mathrm{a}}$ & $76.3 \pm 6.7^{\mathrm{a}}$ \\
$6 \mathrm{hrs}$ & $2.78 \pm 1.5^{\mathrm{bc}}$ & $15.8 \pm 6.7^{\mathrm{bc}}$ & $2.75 \pm 1.17^{\mathrm{bc}}$ \\
$12 \mathrm{hrs}$ & $1.69 \pm 0.9^{\mathrm{bc}}$ & $6.68 \pm 3.03^{\mathrm{bc}}$ & $7.08 \pm 6.06^{\mathrm{bc}}$ \\
$24 \mathrm{hrs}$ & $2.03 \pm 1.6^{\mathrm{bc}}$ & $14.59 \pm 4.62^{\mathrm{bc}}$ & $2.36 \pm 0.2^{\mathrm{bc}}$ \\
$36 \mathrm{hrs}$ & $1.16 \pm 0.6^{\mathrm{c}}$ & $13.87 \pm 3.7^{\mathrm{bc}}$ & $1.03 \pm 0.57^{\mathrm{c}}$ \\
\hline
\end{tabular}

Values are expressed as mean $\pm \mathrm{SD}(\mathrm{n}=4)$. Different superscript letters are significantly different $(\mathrm{P}<0.05)$.

al., 2003; Calame et al., 2008). C. histolyticum group of bacteria has occasionally been associated with inflammation and large bowel disease (Gibson and Roberfroid, 2008; Hughes, 2008).

\subsection{Changes in SCFA concentrations}

The production of lactic acid as the final postbiotic product of the fermentation of both Acacia senegal or inulin shown in Table 6 . Table 6 shows that during the fermentation time from 0 to $6 \mathrm{hrs}$ lactate concentration significantly reduced $(p<0.05)$ for all samples. However, the fermentation time from 6 to $36 \mathrm{hrs}$ did not produce any significant changes in lactate concentration for all samples. Comparing between all samples for each fermentation time showed no significant difference.

The concentration of acetate in the fermentation of Acacia senegal did not significantly increase at the first 6 and $12 \mathrm{hrs}$ compared to $0 \mathrm{hr}$ (Table 7). An increase in acetate concentrations in the fermentation of Acacia senegal was observed only after $12 \mathrm{hrs}$. In the fermentation of inulin, acetate showed a significant increase $(\mathrm{P}<0.05)$ at the first $6 \mathrm{hrs}(73.3 \mathrm{mmol} / \mathrm{L})$ of inoculation. At $6 \mathrm{hrs}$ of fermentation, no significant difference observed for acetate concentration between sample and inulin. Inulin was significantly high $(\mathrm{P}<0.05)$ than Acacia senegal in the production of acetate after 12 and $24 \mathrm{hrs}$ of fermentation, whereas at $36 \mathrm{hrs}$ there were no significant differences in acetate concentration among both samples. As can be seen from the results, the main production of Acacia senegal and inulin fermentation was acetate and followed by propionate. Recently it has been proved by Fukuda et al. (2011), that the production of acetate enhanced intestinal defence mediated by epithelial cell, preventing the host from the infection of enteropathogenic.

Propionate concentration in the colon model fed with either Acacia senegal or inulin at 0, 12, $24 \mathrm{hrs}$ showed no significant difference compared to $0 \mathrm{hr}$ (Table 8). At 36 hrs, Acacia senegal showed significantly high production of Propionate. Comparing between samples, there was no significant difference in Propionate
Table 7. Mean value of acetate concentration (mM) in the colon model at $0,6,12,24$ and $36 \mathrm{hrs}$ inoculated with feces microbiota from obese individuals.

\begin{tabular}{cccc}
\hline Acetate & Senegal & Inulin & Control \\
\hline $0 \mathrm{hr}$ & $11.05 \pm 2.77^{\mathrm{g}}$ & $11.05 \pm 2.77^{\mathrm{g}}$ & $11.05 \pm 2.77^{\mathrm{g}}$ \\
$6 \mathrm{hrs}$ & $50.7 \pm 4.06^{\text {defg }}$ & $73.3 \pm 18.3^{\mathrm{bcd}}$ & $35.14 \pm 6.8^{\mathrm{efg}}$ \\
$12 \mathrm{hrs}$ & $58.19 \pm 3.13^{\mathrm{cdef}}$ & $114.2 \pm 18.5^{\mathrm{ab}}$ & $32.5 \pm 6.7^{\mathrm{bc}}$ \\
$24 \mathrm{hrs}$ & $84.01 \pm 5.2^{\mathrm{bcd}}$ & $133.3 \pm 28.9^{\mathrm{a}}$ & $18.9 \pm 4.5^{\mathrm{fg}}$ \\
$36 \mathrm{hrs}$ & $98.6 \pm 19.1^{\mathrm{abc}}$ & $110 \pm 26.5^{\mathrm{ab}}$ & $19.5 \pm 3.5^{\mathrm{fg}}$ \\
\hline
\end{tabular}

Values are expressed as mean $\pm \mathrm{SD}(\mathrm{n}=4)$. Different superscript letters are significantly different $(\mathrm{P}<0.05)$.

production at $0,6,12 \mathrm{hrs}$ of fermentation. However, at $24 \mathrm{hrs}$, the concentration of Propionate in both Acacia senegal and inulin were significantly higher than control. But at $36 \mathrm{hrs}$, Acacia senegal significantly had the highest concentration of Propionate.

Table 8 . Mean value of propionate concentration $(\mathrm{mM})$ in the colon model at $0,6,12,24$ and 36 hrs inoculated with feces microbiota from obese individuals.

\begin{tabular}{cccc}
\hline Propionate & Senegal & Inulin & Control \\
\hline $0 \mathrm{hr}$ & $23.2 \pm 7.4^{\mathrm{bcd}}$ & $23.2 \pm 7.4^{\mathrm{bcd}}$ & $23.2 \pm 7.4^{\mathrm{bcd}}$ \\
$6 \mathrm{hrs}$ & $23.4 \pm 4.1^{\mathrm{bcd}}$ & $22.4 \pm 4.4^{\mathrm{bcd}}$ & $17.5 \pm 2.5^{\mathrm{cd}}$ \\
$12 \mathrm{hrs}$ & $24.7 \pm 3.9^{\mathrm{bcd}}$ & $38 \pm 7.2^{\mathrm{bc}}$ & $19.04 \pm 3.9^{\mathrm{cd}}$ \\
$24 \mathrm{hrs}$ & $39.4 \pm 4.4^{\mathrm{bc}}$ & $45.5 \pm 13.8^{\mathrm{ab}}$ & $13.2 \pm 4.7^{\mathrm{d}}$ \\
$36 \mathrm{hrs}$ & $64.5 \pm 9.1^{\mathrm{a}}$ & $39.3 \pm 10.6^{\mathrm{bc}}$ & $10.3 \pm 2.7^{\mathrm{d}}$ \\
\hline
\end{tabular}

Values are expressed as mean \pm SD $(n=4)$. Different superscript letters are significantly different $(\mathrm{P}<0.05)$.

In spite of that majority of researches about the antiinflammatory concept of SCFA centered on the impact of acetate (Al-Lahham et al., 2010; Roelofsen et al., 2010), while there is significant prove presenting propionate as a metabolite with a dynamic path against inflammation (Al-Lahham et al., 2012). On the one hand, propionate plays as a ligand of G-protein-couple receptors (GPCR) 41 and 43 (Brown et al., 2003). These receptors when stimulated or activated, lead to significant production of GLP-1 (which could simulate satiety and decrease the gastric emptying) and PYY (be able to control the absorption and digestion of food). Moreover, Maslowaski et al. (2009) found that the drop or lost of GPCR led to serious inflammation. Furthermore, the reduction in plasma levels was noted with the increasing of propionate (Al-Lahham et al., 2010).

The rise in propionate percentage in the fermentation of arabinogalactan treated with obese microbiota proposed that such metabolite of arabinogalactan could prevent inflammation and enhance satiety in obese individuals (Aguirre et al., 2016). So, the increase in propionate and acetate from the fermentation of Acacia senegal may help controlling obesity. Likewise, the chemical structure and composition of gum arabic were probably accountable for SCFA production. Gum arabic, 
singularly Acacia senegal, be able to modify propionate ratios, and this finding is in agreement with the finding from previous researchers (Walter et al., 1988; May et al., 1994; Annison et al., 1995). Together with observations from Annison (1995) results assumed that the increases in propionate production most probably relate to galactose content.

As can be seen from the result, Acacia senegal had no effect on the production of butyrate. Butyrate showed no appreciable production in the inoculation of both Acacia senegal or inulin gum (Table 9). This may be owed to the declined growth of Clostridium in the fermentation of both Acacia senegal and inulin as Clostridium is known to contribute a major fraction of butyrate production (Louis et al., 2010). Butyrate served as the major driving source for the intestinal epithelial cells and plays a significant role in the regulation of cell proliferation and differentiation (Topping and Clifton, 2001).

Table 9. Mean value of butyrate concentration (mM) in the colon model at $0,6,12,24$ and $36 \mathrm{hrs}$ inoculated with feces microbiota from obese individuals.

\begin{tabular}{cccc}
\hline Butyrate & Senegal & Inulin & Control \\
\hline $0 \mathrm{hr}$ & $24.14 \pm 2.3^{\mathrm{a}}$ & $24.14 \pm 2.3^{\mathrm{a}}$ & $24.14 \pm 2.3^{\mathrm{a}}$ \\
$6 \mathrm{hrs}$ & $29.15 \pm 10.3^{\mathrm{a}}$ & $34.2 \pm 7.0^{\mathrm{a}}$ & $21.9 \pm 8.03^{\mathrm{a}}$ \\
$12 \mathrm{hrs}$ & $19.8 \pm 8.6^{\mathrm{a}}$ & $29.61 \pm 10.6^{\mathrm{a}}$ & $25.5 \pm 17.9^{\mathrm{a}}$ \\
$24 \mathrm{hrs}$ & $24.06 \pm 8.7^{\mathrm{a}}$ & $26.12 \pm 7.9^{\mathrm{a}}$ & $17.6 \pm 6.3^{\mathrm{a}}$ \\
$36 \mathrm{hrs}$ & $14.4 \pm 2.3^{\mathrm{a}}$ & $28.3 \pm 6.9^{\mathrm{a}}$ & $16.05 \pm 5.2^{\mathrm{a}}$ \\
\hline
\end{tabular}

Values are expressed as mean $\pm \mathrm{SD}(\mathrm{n}=4)$. Different superscript letters are significantly different $(\mathrm{P}<0.05)$.

Based on Figure 1 acetate: propionate $(\mathrm{A} / \mathrm{P})$ rates were noted to be decreased at $24 \mathrm{hrs}$ and $36 \mathrm{hrs}$ during the fermentation of Acacia senegal. Acetate and propionate play a significant rule in stimulating lipid synthesis (Delzenne and Cani, 2011). As acetate concentrations are higher than those of propionate it is speculative that the ratio of SCFA produced by the obese microbiota is in a sense not "protective" against excess lipid production.

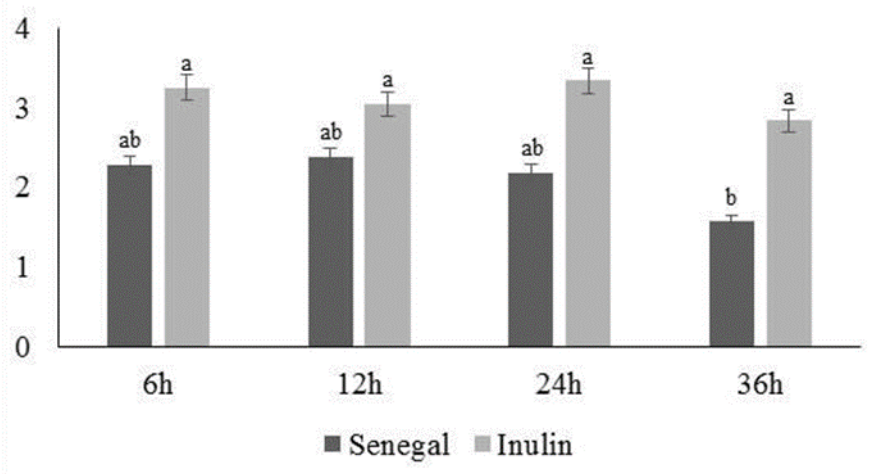

Figure 1. Acetate: propionate rates $(\mathrm{mmol})$ in $\mathrm{pH}$-controlled batch cultures at $0,6,12,24$ and $36 \mathrm{hrs}(\mathrm{n}=4)$. Samples with different letters are statistically different $(\mathrm{p}<0.05)$.
In vitro fermentation of obese microbiotas fed with Acacia senegal showed no significant increase in total SCFAs during the first $6 \mathrm{~h}$ for all samples (Figure 2). For both Acacia senegal and inulin compared to $0 \mathrm{hr}$, increasing the fermentation time up to $36 \mathrm{hrs}$ resulted in a significantly higher $(\mathrm{p}<0.05)$ total SCFA. Thus, higher fermentation time resulted in higher total SCFA production. Interestingly, total SCFA produced in both fermentation (Acacia senegal and inulin) at 24 and 36 hrs did not show any significant difference among both substrates.

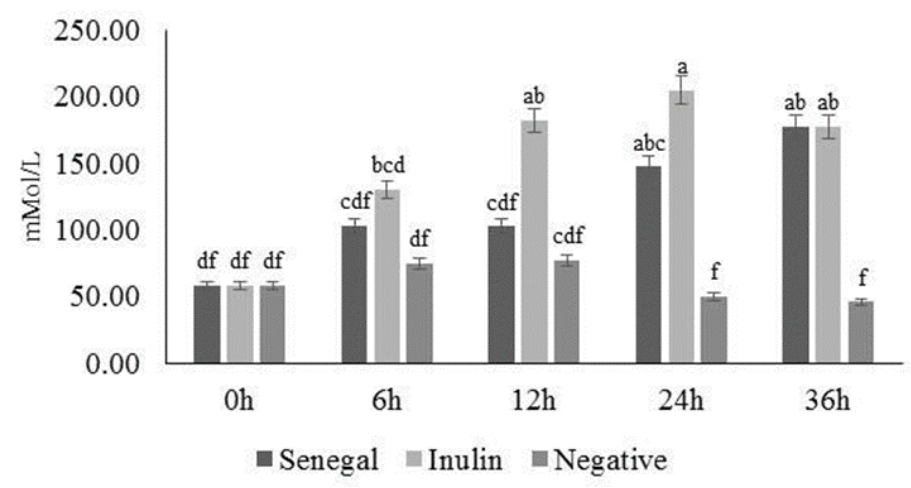

Figure 2. Sum (total) of SCFA obtained after $36 \mathrm{hrs}$ fermentation experiments of Acacia senegal and inulin using obese microbiota. Samples with different letters are statistically different $(\mathrm{p}<0.05)$.

It can also be observed that there is a slow production of SCFAs during the fermentation of Acacia senegal whereas inulin illustrated much higher production of SCFAs. This might be linked to the growth of bacteria which was slow during the early hours of fermentation and then started to increase. By looking at the molecular-weight, gum arabic has complex mixture of heteropolysaccharide with high molecular-weight, whereas inulin is lower in molecular-weight which showed differences in the production of SCFA. However, this observation is in line with the finding of Sarbini et al. (2014), where the oligosaccharides with small molecularweight are much faster fermented than oligosaccharides with bigger molecular-weight.

\section{Conclusion}

This work suggests that Acacia senegal exert an interesting complementary effect. In fact, Acacia senegal changed the colon gut microbiota of obese individuals. Acacia senegal showed increased in bifidobacteria growth in obese individuals. It not only stimulates the bifidobacteria growth but also increases their acidifying activity. However, the growth of probiotic forms SCFAs which in turn have actions at the gut system and a beneficial effect on obesity. The results indicate that Acacia senegal could be a potential novel prebiotic to control obesity. 


\section{References}

Aguirre, M., Bussolo de Souza, C. and Venema, K. (2016). The Gut Microbiota from Lean and Obese Subjects Contribute Differently to the Fermentation of Arabinogalactan and Inulin. PLoS ONE, 11(7), 10.371 . https://doi.org/10.1371/ journal.pone. 0159236

Ahallil, H., Aminah Abdullah., Maskat, M.Y. and Sarbini, S.R. (2018). In Vitro Fermentation of Acacia Senegal by Fecal Microbiota from lean Donors to Stimulate the Growth of Probiotic. Current Trends in Biotechnology and Pharmacy, 12 (1), 96-102.

Ali, B. H., Ziada, A. and Blunden, G. (2009). Biological effects of gum arabic: a review of some recent research. Food and Chemical Toxicology, 47(1), 18. https://doi.org/10.1016/j.fct.2008.07.001

Al-Lahham, S., Roelofsen, H., Rezaee F., Weening, D., Hoek, A. and Vonk, R. (2012). Propionic acid affects immune status and metabolism in adipose tissue from overweight subjects. European Journal of Clinical Investigation, 42(4), 357-364. https:// doi.org/10.1111/j.1365-2362.2011.02590.x

Al-Lahham, S.H., Peppelenbosch, M.P., Roelofsen, H., Vonk, R.J. and Venema, K. (2010). Biological effects of propionic acid in humans; metabolism, potential applications and underlying mechanisms. Biochimica et Biophysica Acta, 1801(11), 11751183.

Anderson, J.W., Baird, P., Davis, R.H., Ferreri, S., Knudtson, M. and Koraym, A. (2009). Health benefits of dietary fiber. Nutrition Reviews, 67(4), 188-205. 4887.2009.00189.x

Annison, G., Trimble, R.P. and Topping, D.L. (1995). Feeding Australian acacia gums and gum arabic leads to non-starch polysaccharide accumulation in the cecum of rats. Journal of Nutrition, 125(3), 283292.

Brinkworth, G.D., Noakes, M., Clifton, P.M. and Bird, A.R. (2009). Comparative effects of very lowcarbohydrate, high-fat and high-carbohydrate, lowfat weight-loss diets on bowel habit and faecal shortchain fatty acids and bacterial populations. British Journal of Nutrition, 101(3), 1493-1502. https:// doi.org/10.1017/S0007114508094658

Brown, A.J., Goldsworthy, S.M, Barnes, A.A, Eilert, M.M, Tcheang, L. and Daniels, D. (2003). The Orphan G protein coupled receptors GPR41 and GPR43 are activated by propionate and other short chain carboxylic acids. Journal of Biological Chemistry, 278(13), 11312- 11319. https://
doi.org/10.1074/jbc.M211609200

Cani, P.D., Lecourt, E., Dewulf, E.M., Sohet, F.M., Pachikian, B.D., Naslain, D., De Backer, F., Neyrinck, A.M. and Delzenne, N.M. (2009). Gut microbiota fermentation of prebiotics increases satietogenic and incretin gut peptide production with consequences for appetite sensation and glucose response after a meal. American Journal of Clinical Nutrition, 90(3), 1236-1243. https://doi.org/10.3945/ ajcn.2009.28095

Chandalia, M., Garg, A., Lutjohann, D., von Bergmann, K., Grundy, S.M. and Brinkley, L.J. (2000). Beneficial effects of high dietary fiber intake in patients with type 2 diabetes mellitus. The New England. Journal of Medicine, 342(19), 1392-1398. https://doi.org/10.1056/NEJM200005113421903

Collado, M.C., Isolauri, E., Laitinen, K. and Salminen, S. (2010). Effect of mother's weight on infant's microbiota acquisition, composition, and activity during early infancy: a prospective follow-up study initiated in early pregnancy. American Journal of Clinical Nutrition, 92(3), 1023-1030. https:// doi.org/10.3945/ajen.2010.29877

Collado, M.C., Meriluoto, J. and Salminen, S. (2007). In vitro analysis of probiotic strain combinations to inhibit pathogen adhesion to human intestinal mucus. Food Research International, 40(3), 629-636. https://doi.org/10.1016/j.foodres.2006.11.007

Cummings, J., Pomare E., Branch, W., Naylor, C. and Macfarlane, G. (1987). Short chain fatty acids in human large intestine, portal, hepatic and venous blood. Gut, 28(7), 1221- 1227 . https:// doi.org/10.1136/gut.28.10.1221

Eaton, S.B. and Konner, M. (1985). Paleolithic nutrition: a consideration of its nature and current implications. New England Journal of Medicine, 312(2), 283-289. https://doi.org/10.1056/NEJM198501313120505

European Food Safety Authority. (2010). Scientific opinion on dietary reference values for carbohydrates and dietary fibre. EFSA Journal, 8, 1-77. https:// doi.org/10.2903/j.efsa.2010.1462

Franks, A.H., Harmsen, H.J.M. and Raangs, G.C. (1998). Variations of bacterial populations in human feces measured by fluorescent in situ hybridization with group-specific 16s rRNA-targeted oligonucleotide probes. Applied and Environmental Microbiology, 64(9), 3336-3345. https://doi.org/10.1128/ AEM.64.9.3336-3345.1998

Freeland, K.R and Wolever, T.M. (2010). Acute effects of intravenous and rectal acetate on glucagon-like peptide-1, peptide YY, ghrelin, adiponectin and tumour necrosis factor-alpha. British Journal of 
Nutrition, 103(3), 460-466. https://doi.org/10.1017/ S0007114509991863

Fukuda, S., Toh, H. and Hase, K. (2011). Bifidobacteria can protect from entropathogenic infection through production of acetate. Nature, 469(4), 543-547. https://doi.org/10.1038/nature09646

Gibson, G.R., Probert, H.M. and Loo, J.V. (2004). Dietary modulation of the human colonic microbiota: updating the concept of prebiotics. Nutrition Research Reviews, 17(2), 259-275. https:// doi.org/10.1079/NRR200479

Harmsen, H.J.M., Elfferich, P. and Schut, F. (1999). A 16s rRNA targeted probe for detection of lactobacilli and enterococci in faecal samples by fluorescent in situ hybridization. Microbial Ecology in Health Disease, 11(6), 3-12. https:// doi.org/10.1080/089106099435862

Kalliomaki, M., Collado, M.C., Salminen, S. and Isolauri, E. (2008). Early differences in fecal microbiota composition in children may predict overweight. American Journal of Clinical Nutrition, 87(8) 534-538. https://doi.org/10.1093/ajcn/87.3.534

Korpela. K., Flint. H.J., Johnstone, A.M., Lappi, J., Poutanen, K. and Dewulf, E. (2014). Gut microbiota signatures predict host and microbiota responses to dietary interventions in obese individuals. PLoS One, $9(6), \quad 2460-2471 . \quad$ https://doi.org/10.1371/ journal.pone.0090702

Langendijk, P., Schut, F. and Jansen, G. (1995). Quantitative fluorescence in situ hybridization of Bifidobacterium spp. with genus-specific 16s rRNAtargeted probes and its application in fecal samples. Applied and Environmental Microbiology, 61(2), 3069-3075. https://doi.org/10.1128/AEM.61.8.30693075.1995

Liu, S., Willett, W.C., Manson, J.E., Hu, F.B., Rosner, B. and Colditz, G. (2003). Relation between changes in intakes of dietary fiber and grain products and changes in weight and development of obesity among middle-aged women. American Journal of Clinical Nutrition, 78(5), 920-927. https:// doi.org/10.1093/ajen/78.5.920

Lunn, J. and Buttriss J. (2007). Carbohydrates and dietary fibre. Nutrition Bulletin, 32(3), 21- 64. https://doi.org/10.1111/j.1467-3010.2007.00616.x

Manz, W., Amann, R. and Ludwig, W. (1996). Application of a suite of 16s rRNA-specific oligonucleotide probes designed to investigate bacteria of the phylum cytophaga- flavobacterbacteroides in the natural environment. Microbiology, 142(7), 1097-1106. https:// doi.org/10.1099/13500872-142-5-1097
Maslowski, K.M., Vieira, A.T., Ng, A., Kranich, J., Sierro, F. and $\mathrm{Yu}$, D. (2009). Regulation of inflammatory responses by gut microbiota and chemoattractant receptor GPR43. Nature, 461(8), 1282-1286. https://doi.org/10.1038/nature08530

May, T., Mackie, R.I., Fahey, G.G., Cremin, J.C. and Garleb, K.A. (1994). Effect of fiber source on shortchain fatty acid production and on the growth and toxin production by Clostridium difficile. Scandinavian Journal of Gastroenterology, 19(5), 916-922.

https:// doi.org/10.3109/00365529409094863

McNeil, N. (1984). The contribution of the large intestine to energy supplies in man. American Journal of Clinical Nutrition, 39(3), 338-342. https://doi.org/10.1093/ajen/39.2.338

Murphy, E., Cotter, P., Healy, S., Marques, T., O'Sullivan, O. and Fouhy, F. (2010). Composition and energy harvesting capacity of the gut microbiota: relationship to diet, obesity and time in mouse models. Gut, 59(8), 1635-1642. https:// doi.org/10.1136/gut.2010.215665

Nguyen, D.M. and El-Serag, H.B. (2010). The epidemiology of obesity. Gastroenterology Clinical of North America, 39(2), 1-7. https:// doi.org/10.1016/j.gtc.2009.12.014

Peran, L. (2007). A comparative study of the preventative effects exerted by three probiotics, Bifidobacterium lactis, Lactobacillus casei and Lactobacillus acidophilus, in the TNBS model of rat colitis. Journal of Applied Microbiology, 103(4), 836 -844 . https://doi.org/10.1111/j.13652672.2007.03302.x

Popkin, B.M., Adair, L.S. and Ng, S.W. (2012). Global nutrition transition and the pandemic of obesity in developing countries. Nutrition Reviews, 70(2), 321. https://doi.org/10.1111/j.17534887.2011.00456.x

Popovich, D.G., Jenkins, D.J., Kendall, C.W., Dierenfeld, E.S., Carroll, R.W. and Tariq, N. (1997). The western lowland gorilla diet has implications for the health of humans and other hominoids. Journal of Nutrition, 127(6), 2000-2005. https:// doi.org/10.1093/jn/127.10.2000

Prentice, A.M. and Jebb, S.A. (2003). Fast foods, energy density and obesity: a possible mechanistic link. Obesity Reviews, 4(3), 187-194. https:// doi.org/10.1046/j.1467-789X.2003.00117.x

Reimer, R.A, Maurer, A.D., Eller, L.K., Hallam, M.C., Shaykhutdinov, R. and Vogel, H.J. (2012). Satiety hormone and metabolomic response to an intermittent high energy diet differs in rats 
consuming long-term diets high in protein or prebiotic fiber. Journal of Proteome Research, 11(2), 4065-4074. https://doi.org/10.1021/pr300487s

Roberfroid, M.B., Van Loo, J.A.E. and Gibson, G.R. (1998). The bifidogenic nature of chicory inulin and its hydrolysis products. Journal Nutrition, 128(8), 89. https://doi.org/10.1093/jn/128.1.11

Roelofsen, H., Priebe, M.G. and Vonk, R.J. (2010). The interaction of short-chain fatty acids with adipose tissue: relevance for prevention of type 2 diabetes. Beneficial Microbes, 1(4), 433-437. https:// doi.org/10.3920/BM2010.0028

Royall, D., Wolever, T.M. and Jeejeebhoy, K.N. (1990). Clinical significance of colonic fermentation. The American Journal of Gastroenterology, 85(10), 1307 -1312 .

Rycroft, C.E., Jones, M.R., Gibson, G.R. and Rastall, R.A. (2001). A comparative in vitro evaluation of the fermentation properties of prebiotic oligosaccharides. Journal of Applied Microbiology, 91(9), 878-887. https://doi.org/10.1046/j.13652672.2001.01446.x

Sarbini, S.R. and Rastall, R.A. (2011). Prebiotics: metabolism, structure and function. Functional Food Reviews, 3(11), 93-106.

Sarbini, S.R., Kolida, S., Deaville, E.R., Gibson, G.R. and Rastall, R.A. (2014). Potential of novel dextran oligosaccharides as prebiotics for obesity management through in vitro experimentation. British Journal of Nutrition, 112(10), 1303-1314. https://doi.org/10.1017/S0007114514002177

Sartor, R.B. (2008). Therapeutic correction of bacterial dysbiosis discovered by molecular techniques. Proceeding of the National Academy of Science U. S. A., 105, 16413-16414. https://doi.org/10.1073/ pnas. 0809363105

Slavin, J. (2003). Why whole grains are protective: biological mechanisms. Proceedings of the Nutrition Society, 62(1), 129-134. https://doi.org/10.1079/ PNS2002221

Slavin, J. (2013). Fiber and prebiotics: mechanisms and health benefits. Nutrients, 5(4), 1417-1435. https:// doi.org/10.3390/nu5041417

Tarini, J. and Wolever, T.M. (2010). The fermentable fibre inulin increases postprandial serum short-chain fatty acids and reduces free-fatty acids and ghrelin in healthy subjects. Applied Physiology, Nutrition, and Metabolism, 35(1), 9- 16. https://doi.org/10.1139/ H09-119

Terpend, K., Possemiers, S., Daguet, D. and Marzorati, M. (2013). Arabinogalactan and fructooligosaccharides have a different fermentation profile in the Simulator of the Human Intestinal Microbial Ecosystem (SHIME). Environmental Microbiology Reports, 5(4), 595-603. https:// doi.org/10.1111/1758-2229.12056

Tyler, V.B. and Robbers, L. (1977). Pharmacognosy., p. 64-68. Philadelphia: Lea and Febiger.

Van Nuenen, M.H., Venema, K., van der Woude, J.C. and Kuipers, E.J. (2004). The metabolic activity of fecal microbiota from healthy individuals and patients with inflammatory bowel disease. Digestives Diseases and Sciences, 49(2), 485-491. https:// doi.org/10.1023/B:DDAS.0000020508.64440.73

Walter, D.J., Eastwood, M.A., Brydon, W.G. and Elton, R.A. (1988). Fermentation of wheat bran and gum arabic in rats fed on an elemental diet. British Journal of Nutrition, 60(6), 225-232. https:// doi.org/10.1079/BJN19880094

Wong, J.M., de Souza, R., Kendall, C.W., Emam, A. and Jenkins, D.J. (2006). Colonic health: fermentation and short chain fatty acids. Journal of Clinical Gastroenterology, 40(9), 235- 243. https:// doi.org/10.1097/00004836-200603000-00015

Zeuthen, L., Fink, L.N., Metzdorff, S.B., Kristensen, M.B., Licht, T.R., Nellemann, C.L. and Frøkiær, H. (2010). Lactobacillus acidophilus induces a slow but more sustained chemokine and cytokine response in naive foetal enterocytes compared to commensal Escherichia coli. BMC Immunology, 11(6), 222-234. https://doi.org/10.1186/1471-2172-11-2 